\title{
A Study on the Origin of Cangxi Unicorn Dance
}

\author{
Min An \\ Ba Culture Institute in Sichuan University of Arts and Science, Dazhou, China \\ Email: 47872614@qq.com
}

How to cite this paper: An, M. (2020). A Study on the Origin of Cangxi Unicorn Dance. Open Journal of Social Sciences, 8 , 13-23.

https://doi.org/10.4236/jss.2020.812002

Received: November 19, 2020

Accepted: November 29, 2020

Published: December 2, 2020

Copyright $\odot 2020$ by author(s) and Scientific Research Publishing Inc. This work is licensed under the Creative Commons Attribution International License (CC BY 4.0).

http://creativecommons.org/licenses/by/4.0/

\section{(c) (i) Open Access}

\begin{abstract}
There are many places of unicorn dance in China; most of the unicorn dances of the same name in other places, however, can only be found in the list. There are few detailed studies, only Cangxi unicorn dance has rich information, and it is described in relative detail in "Cangxi County Chronicles" and "Chinese Dance Chronicles". In terms of performance forms, performance characteristics and cultural connotation, Cangxi unicorn dance has some similarities with southern lion and unicorn dance, but its individual characteristics are more obvious. As a result, if we want to understand the origin of Cangxi unicorn dance, we must clarify the relationship between Cangxi unicorn dance and other similar dances, and understand the unique historical, cultural and geographical environment of Cangxi in order to better know its origin. Therefore, this paper will study the unicorn from three aspects: the introduction of Unicorn, the source of Unicorn image and the relationship with the South lion.
\end{abstract}

\section{Keywords}

Cangxi Unicorn Dance, Intangible Cultural Heritage, Comparative Study, The Study of the Original

\section{Introduction}

Cangxi unicorn dance, as a provincial intangible cultural heritage, is still active in Cangxi County, Sichuan Province. For example, Cangxi County Chronicles compiled by Cangxi County Chronicles compilation Committee, Cangxi Literature and Art, an internal publication of Lingjiang Town Cultural Station in Cangxi County, or the legends and performances of "Unicorn Dance" are all described. For example, there are records of unicorn lanterns in the Cultural Chronicles of Cangxi County compiled by Zhang Guoying, a native of Cangxi County. These achievements are from the perspective of description and introduction to record the unicorn dance; the content is relatively simple. In addition, 
there are also some profiles about unicorn dance on the Internet, most of which are less than 200 words, and some of the authenticity of the content remains to be confirmed. Generally speaking, there is a lack of "in-depth" research on Cangxi unicorn dance; therefore, it is of academic and practical value to study the origin and development of Cangxi unicorn dance and explore the relationship between other similar dances.

\section{Introduction of Cangxi Unicorn Dance}

\subsection{The Age of Unicorn Dance}

The existing unicorn data say that the Cangxi unicorn dance originated in the Ming Dynasty, but there is no reliable record in the specific literature. Ten rituals in the Chronicles of Cangxi County of the Republic of China recorded: "the colleges and universities on the fifteenth day of the first lunar month (commonly known as the Lantern Festival), the old custom from the 9th to the Lantern Festival, one is the dragon lantern ... the other is the lion lantern ... and the unicorn lantern." From the word "old custom" here, we can see that unicorn dance has been popular in Cangxi for a long time, at least before the Republic of China. Through the analysis of its specific image, we can see that it has no resemblance to the image of Yuanyu before the Northern Dynasty, only one feature is similar, so it can only appear after the Northern Dynasty, and its colorful Linjia is similar to the unicorn, while the appearance of the unicorn is seen in the literature, it was during the Wanli period of the Ming Dynasty, so the dance should be after the Ming Wanli. Above we know that the Cangxi unicorn dance appeared because of the tiger disease, and the Cangxi tiger disease was the most violent in the late Ming and early Qing dynasties, so we can preliminarily conclude that it appeared at the end of the Ming Dynasty. Therefore, the earliest unicorn dance in Cangxi appeared in the late Ming Dynasty, and the latest in the Qing Dynasty, which has a history of about 400 years.

\subsection{The Performance of Unicorn Dance}

In the last century, because Cangxi Cultural Station was located in Yancong Temple in Cangxi Shaoping Mountain, unicorn dance performances started from Yancong Temple, before departure, you need to worship Buddha and burn incense to pray for a smooth trip. After worshiping the Buddha, firecrackers were set off and trombone was played, and a series of "Wudududu" sounds from more than 4-foot-long bamboo trumpets resounded through both sides of the Jialing River, so that people in the whole county knew it was a unicorn dance. Through the interpretation of the two similar dance ceremonies, we can see that the dance attaches importance to religious beliefs and conveys the consistency of cultural connotations. The magnificent appearance represents the status of the subject of "dance" and shows that unicorns and lions are the same symbol in people's hearts.

Unicorn dance in the unicorn, the head of the unicorn, eyes such as bronze 
bell, blood mouth ferocious teeth, a few feet under the Hubei long beard, body such as tiger, such as lion, covered with colorful Linnaeus, long tail, a total length of about 2.8 meters. The performance style and characteristics of the dance is the essence of a dance, and the performance procedure of the unicorn can be divided into three parts: the performance on the ground: worship the four directions, and the unicorn dances according to the shape of the monster. shaking the head, swinging the tail, swinging the beard, shaking the nail, teething, claw, rolling, rolling, galloping, nibbling, licking, scratching, palming and other movements, platform performance: performing on several or even more than a dozen square tables. This is called "the upper tiger and the lower tiger" by professional unicorn dancers, while the audience or professionals will use the stone nest to put pig skin, explosives, bacon and iron in it, and then light it up and burn the unicorn with fire. You can also throw fireworks at the unicorn with torches, firecrackers, fireworks and firecrackers, forming a spectacular scene of besieging monsters on all sides. Firecrackers sparks or explode at the top of the head, or fired at the feet, or burned in the abdomen and back, smoke eyes choking nose, the performer dancing the head of the animal, swinging left and right, shaking tentacles, shaking scales, driving unicorns cannot look at each other, showing a vivid appearance. This is the best part of the unicorn dance, known as the "Burning Unicorn". Finally, the dancers come down from the high platform and end the performance on the flat ground. There are various forms of southern lion performance, among which the high platform performance is the same as the unicorn dance platform performance: the high platform is made up of four tables, with one table, three tables or six tables stacked on the platform, and the lion dancers go up to the platform with different body methods such as straight jump and rotation. Perform difficult movements such as lion-carrying lion, lion-carrying man, and two lions standing on their claws on a high platform. The lion landed with a leap, front (or back, or side) somersault.

\section{The Image Source of Cangxi Unicorn Dance}

\subsection{Evolution of Unicorn Image}

The unicorn was first called the unicorn. There are many records in the literature about haechi. "The Records of Foreign bodies" written by Yang Fu in the Eastern Han Dynasty recorded: "there are beasts in the wilderness of the northeast, the name of the beast, a horn, character loyalty, see people fight, then touch not straight, hear about people, then how not correct." Wang Fu in the Western Jin Dynasty recorded: "in the wilderness of the northeast, there are animals such as sheep, a corner, blue fur, four feet, straight in nature, but not straight when you see a man fighting." the name is haechi, other name is Renfashou. It was also recorded in "Narrate different ti write down" of $\mathrm{Zu}$ Chongzhi in the Southern Dynasty that "haechi, the sheep with one horn is familiar with human nature". It can be seen that before the Southern Dynasty, the haechi had the shape of a sheep and artificially constructed a single horn. A large number of haechi have 
been unearthed in Gansu. There are two types of bronze and wood in the Gansu Museum. Most of the wooden ones are painted in color, while the bronze is colorless, which is slightly more magnificent, but on the whole, the unearthed ones are basically consistent with the above literature records: they have the shape of a sheep, one-horned front thorns, pointed tails facing the sky, arms and legs straddling forward, with iconic horns and straight tails of 90 degrees, with slightly the same length and width, the limbs are stout, exaggerated but coordinated. After the Northern Dynasty, the image of haechi has changed, compared with the previous image, the style of the Northern Dynasty pottery unicorn exhibited by the Shaanxi History Museum is quite different: it has changed from sheep-shaped to ox-shaped, with shorter long horns and wings on the back. the overall style tends to be stable and soothing, which is quite different from the previous sharp and fierce. In the Tang and Song dynasties, the haechi was often used as a tomb beast in the town. In order to meet the needs of social function, it integrated the characteristics of the unicorn and finally formed a combination of cow head, deer body and horseshoe. There were no wings on the back, and the single horn was still an important symbol. The mausoleum of Tang Ruizong named Li Dan is the earliest and only mausoleum in Tang mausoleum had haechi: its head is like an ox, its head stands on a single horn, its deer body is horseshoe, it is strong, its body is full, its waist and neck are muddy and round, and its limbs are as short and thick as columns. The tail is dragged down and connected to the pedestal. The face of the auspicious animal is difficult to determine, its teeth are bared, its tusks are exposed, its eyes are round and its nostrils are enraged, it looks ferocious and ferocious, and its ears are close to its forehead and seem to be extremely alert (Sun, 1987). The image of the Ming and Qing dynasties is different from that of the Tang and Song dynasties, generally returning to nature, less depiction, heavy appearance, single horn, ox body, ponytail, no wings, ferocious facial expression, but the expression is more introverted than that of the Tang and Song dynasties, and the overall image is stable. Looking at the changes in the shape of the haechi mentioned above, we can see that with the changes of the times and the needs of social functions, the image of the haechi is cumbersome, and the images of different times are quite different, but the overall characteristics of the single horn are retained. The style is "ferocious" and "dignified and serious".

In addition to the gazelle, the ancient immortal beasts such as the unicorn also had the characteristics of a single horn, and their shape was similar to that of the mahogany, so a little comparison is made here. "Erya. Shi Beast" said that the shape of the unicorn: "Lin, Milu body, oxtail, horn", in the Qin and Han dynasties, because the unicorn had a single horn, it was also called a unicorn (Weng, 2008). In the Song Dynasty, Kirin has no unique characteristics. Taiping Imperial Lane said: "Kylin, benevolent beast, horse body, oxtail, meat horn." to the Ming Dynasty, Kylin appeared on Kylin, "Dantu County Chronicles": "in the 21 years of Wanli, a cow was produced by a Zhuwang family in Tangliwan. Xian- 
wang family had red light every night, rising like fire, and Lin was no longer seen after giving birth." The Modern Chinese Dictionary gives the following explanation to Kylin: "it is shaped like a deer, with horns on its head, scaly armour all over its body, and a tail like an ox's tail." Throughout the evolution of the image of the unicorn, the unicorn has always had the characteristics of deer body and oxtail, while in the evolution is its single horn and scale armour, which gradually disappears with the social changes, and the scale armor is more and more dense, but the overall image is more similar to that of the maze. In addition to Kirin, a tiger-shaped unicorn was unearthed in the Han Tomb of Changlin, Mianxian County, Qinba Mountain area in southern Shaanxi, with the same body size as a tiger, but a single horn on its head, known as a tiger-shaped unicorn, did not appear in other places. This may be related to the special geographical environment of the Qin-Ba Mountains. Volume 10 of Huayang Guozhi recorded that "during the time of King Zhaoxiang of Qin, the white tiger suffered from Qin, Shu, Ba and Han Dynasty." Guo Qinghua believes that the tiger leopard in the Qin-Ba mountains of the Han Dynasty was the king of all beasts, and Megatron was in all directions, so people shaped tiger-shaped unicorns according to the tiger shape and the characteristics of the haechi (Guo, 1991). And the tiger-shaped unicorn only appeared in the tomb of the Han Dynasty, and the descendants did not see it, so it should be integrated with other auspicious animals and eventually evolved into other images.

\subsection{When Did the Word Unicorn Appear?}

And when exactly did the word unicorn come into being? From the 7th century to the 10th century, Dunhuang changed the text in the Tang Dynasty: "what gives birth to a unicorn is expressed in the praise of the Great Saints alone. The nine gods of the younger brother opened the hidden ones, the hidden ones in the earth." This is the earliest description of the word unicorn in the literature. since the Tang Dynasty, the word unicorn rarely appeared in the text, and it did not appear widely until the Ming and Qing dynasties, Chen Jiru's Tiger in Ming Dynasty and Yongzheng's Shaanxi Tongzhi in Qing Dynasty have the same records: "there are unicorns in Baoji County, and woodcutters see them lying in the forest, or fighting tigers and eating them." The Story of the West: "my mother was furious and shouted, 'where is the unicorn'? This unicorn was originally a bird on Xumi Mountain, it was shaped like a sheep, but it was more than ten feet tall and more than three feet long. A horn was born on its forehead, like a heavenly fork." The Romance of God in the Ming Dynasty: volume 19, "Jin Dasheng was furious and urged to open the unicorn and cut the three-pointed knife. Zheng Lun's pestle split noodles to meet each other, the two beasts intersect, and the war coincided." Yin Guangren and Zhang Rulin, A brief account of Qianlong Macao: "the unicorn is as big as a horse, with yellow hair, horned head, four or five feet long, and its sharpness can touch a big lion." 13 and 14 the Uighur epic the Legend of Urgus Khan has the word "kiat", which is described as: "in this forest, there is a big unicorn, which eats many people and animals." It 
is a very ferocious beast. It brought great pain to people. Urgus Khan was a fearless hero who wanted to hunt this unicorn. It can be seen that the word unicorn appeared in the Buddhist literature in the early stage, but its specific image was unknown, in the Ming and Qing dynasties, the unicorn looked like a sheep. It can be seen that in the Ming and Qing dynasties, the unicorn followed the shape of the sheep, which was obviously different from that of the tomb beasts in the Ming and Qing dynasties, however, it is characterized by "as big as a horse", "more than ten feet tall", "more than three feet long" and "fighting a tiger and eating", it can be seen that it is fierce and fierce, combined with the description of different nationalities and regions, unicorns can also be said to be the common name of unicorns. Due to the development of science and the improvement of information technology, unicorns are often used in the economic field as a referential pronoun with outstanding referential ability or outstanding image, which is far from the image in the ancient literature.

\subsection{The Formation of Cangxi Unicorn Dance}

Cangxi belongs to Ba region since ancient times, and it is not difficult to speculate that it has experienced a tiger disaster. Wang Shizhen in the Qing Dynasty once wrote "Tiger jumping Station": "Road teases Cangxi County, desolation and destruction of the post. Boats are rarely seen in gold, you will close the door early", "there are people who plough the fields, those who are swallowed by tigers during the day, those who live in rural areas, those who are eaten by tigers at night: and in various states and counties, where city walls collapse, and tigers also go straight to eat." in the late Ming and early Qing dynasties, the county magistrate of Cangxi also had a record of sighing about the tiger plague. Therefore, it is true that Cangxi suffered a serious tiger epidemic in the late Ming and early Qing dynasties. So does the image of Cangxi unicorn dance come from tiger-shaped haechi? What does he have to do with the haechi (unicorn) and the unicorn? Cangxi unicorn dance was initially known as "burning unicorn", the performance is adventurous and exciting, especially fire as the main point. As mentioned above, the image of the unicorn has no specific animals to refer to, its unicorn is the same as the beard, the long beard under the $\mathrm{E}$ is similar to the lion, and the body is more like the unicorn. It can be seen that the image of the Cangxi unicorn dance comes from the synthesis of all kinds of auspicious animals. According to the inheritor of Cangxi unicorn dance, the reason for adopting "unicorn" as the dance image is to take the meaning of "king of beasts", and "king of beasts" is aimed at the ferocious degree of animals. Although this kind of ferocity is man-made, it has a certain realistic basis. According to the fact that there are many tigers in Badi, we naturally think that this kind of ferocity is certainly aimed at tigers, because predators in Cangxi have not been common since ancient times, and only tigers have been affected. To sum up, the Cangxi unicorn dance should be a dance form evolved from the awe of the tiger, initially taking the tiger-shaped unicorn as the object, absorbing the characteristics of the unicorn and lion in the process of evolution, and gradually forming the present 
appearance. The dance first reflects the hardship of people's natural conditions and the confrontation between man and nature in ancient society, and the other is the primitive worship of ferocious animals.

\section{The Performance Characteristics of the Unicorn Dance: A Comparison with the Southern Lion Dance}

\subsection{The Comparison of Legends between Cangxi Unicorn Dance and the Southern Lion Dance}

The southern lion dance, also known as the dance lion and the spirit lion, was born from the northern lion and derived many schools. Because the Northern Lion was used by the court in the Tang Dynasty, in order to avoid the royal taboo of the Northern Lion, the folk created the Southern Lion according to the Northern Lion. In the process of creation, it was distinguished from the Northern Lion as far as possible from the production and performance form of the Northern Lion (Huang, 2001). Finally, the integration of folk customs and culture forms a modern southern lion system and performance mode. The biggest difference between the southern lion and the northern lion is that there is a single horn on the forehead, which can also be called "unicorn dance" if tracked down by the government (Gao \& Yao, 2007). From this level, after the Tang Dynasty, the southern lion may also be called the unicorn dance. In today's Vietnam and other places, the unicorn dance and the southern lion dance are still the common name of the same dance mode. Compared with the existing three types of dances in China, they do have similar characteristics, therefore, in order to better clarify the characteristics and historical origin of unicorn dance, it is necessary to make a comparative study of unicorn dance and southern lion dance.

As early as $1386 \mathrm{AD}$, in the early Ming Dynasty, the southern lion of Foshan, Guangdong, had already taken shape. It is said that in the early Ming Dynasty, a monster appeared in Foshan, Guangdong, which wasted crops everywhere, maiming people and animals, and rural farmers could not bear its suffering. Later, people came up with a way to make many lion models with strips, painted with various mottled colors, and arranged in advance. When the monster appeared, the gongs and drums sang in unison, the lions danced, the monster was frightened, turned around and ran away. Since then, the local villagers think that lions have the ability to exorcise evil spirits and have auspicious signs. People hope that the lion can dance in front of the house to eliminate the disaster. Forecast auspicious, so every Spring Festival, beating gongs and drums, door-to-door lion dance New year to form a custom. According to textual research and inheritors, the folklore of Cangxi unicorn dance also originated from "beasts eat crops": it is said that during the Ming Dynasty, there was a temple in Zhaojiashan, Cangxi County, where unicorns were worshiped by torrential rain, the unicorns went down the mountain from the single-mouth beam of Zhaojiashan and entered the Jialing River (Jialing River is located in the foothills of 
Zhaojiashan), as soon as the unicorns entered the river, the water in the Jialing River was separated from the middle to both sides, the pebbles and leaves at the bottom of the river all float to the surface, which is surprising to the people of Cangxi. The unicorn then came to the water village of Cangxi County. At noon, people along the way saw the unicorn eating crops, and the footsteps of passers-by disturbed the unicorn. The unicorn wanted to eat the passers-by, and the passers-by were terrified, he had the courage to ask the unicorn: if you want to eat me, please nod. If you don't eat me, I will take you to the people. After listening to the unicorn, the unicorn did not eat the passers-by, so the passer-by brought the unicorn to the folk, and then Zhaojiashan in Cangxi County also began to have unicorn dance. Compared with the two kinds of folklore, there are striking similarities, both describing the phenomenon of beasts attacking crops and human beings, and also showing people's awe and worship of beasts, so they hope to achieve the purpose of eliminating disasters by dancing in the image of beasts. In general, folklore does not need real history, but it is not inseparable from history, and reflects a certain historical basis, which makes the storyline appear authentic, so the folklore of Guangdong and Cangxi is based on some kind of historical connection. Shaped the same fact, that is, the attack of the beast. At the same time, due to the different national culture, the needs of mass collective activities and the level of development in our country, there are different origins and opinions, therefore, although the legend of Cangxi unicorn and the legend of "Nian" in Foshan, Guangdong have the same historical basis, the places, characters and events involved are not the same, in order to be more in line with the local reality, so as to be more real. Since the legend of "unicorn" appears on the basis of unicorn dance, it should appear at the same time, so it should be defined as the end of the Ming Dynasty. Compared with the legend of "Nian", it should be delayed for hundreds of years. We can say that the legend of unicorn may learn from the legend of "Nian", but it is also possible that both legends originated locally and originated from local historical events, but they have gone through layers of tiredness in a long time, the events occurred in different times and different regions are glued together to form the current legends.

\subsection{The Comparison of Performance and Production Methods between Cangxi Unicorn Dance and the Southern Lion Dance}

In addition to Foshan, Guangdong, the Ling Lion in Tuan ran Township, Changsha County, Hunan Province also belongs to the southern lion genre. The lion dance in Tuan ran Township has a strong religious color and is the symbol of the "lion god", whenever the lion dance team starts to perform, it is bound to start from the temple, with a great momentum, three miles away, firecrackers, the sound of fire, horn horn, resounding through the sky. The high-platform performance part of the similar Cangxi unicorn dance has more similarities with the high-platform performance part of the southern lion (the details of Cangxi Unicorn dance's performance is described earlier), the props of the performance 
are all square tables, and the forms of the performance are all from the bottom to the top of the stage. then according to their respective performance skills to show movements consistent with the image, to achieve thrilling, exciting and beautiful effect at the same time, in order to attract the attention of the audience.

In addition to the way of performance, the production of Cangxi unicorn is also consistent with that of the southern lion, both of which are bound with bamboo strips and then mounted with paper or cloth. After this step, the basic shape of the animal has been completed, and there is a big difference in the external decoration between the two. The body part of the unicorn has a total of two layers of white cloth to be painted, and the outermost layer needs to be painted and pasted with scales. And spray the whole unicorn with salt water. But the southern lion does not need to be painted, but with hair.

From the comparison of the Cangxi unicorn dance and the southern lion from the folklore, performance and production methods, we can see that there are many similarities between the two, but the two are thousands of miles apart, and it is difficult to communicate with each other in ancient times. Cultures rarely influence each other, so how did this similarity come into being? According to the Chronicles of Cangxi County: "The local people are all gone, in the early Qing Dynasty, they touted exile, accounting for only four or five of the ten, and most of them were engaged in farming." In the early Qing Dynasty, the population of other provinces migrated back and forth to Cangxi for naturalization and employment. In the seventh year of Emperor Kangxi, Sichuan tamed Zhang Dedi and said: "Chachuan Province is a relic, most of its ancestors are from $\mathrm{Hu}$ guang people, and they visit the townships. They all say that every disaster in Sichuan since the past, there must be soil and no one, so people in other provinces have no choice but to move to fill places. Therefore, there are more people who are originally from Huguang Macheng." The 1993 edition of Chronicles of Cangxi County shows that most of the population of Cangxi comes from Hunan, Hubei, Guangdong, Guangxi, Fujian, Zhejiang, Shaanxi and so on. We know that Guangdong and Sichuan have had a very close relationship in history: $\mathrm{Hu}-$ guang filled Sichuan, and the population, culture and customs of the two places have been thoroughly integrated and changed. Under this connection, it is not surprising that there is a connection between the two dances. Therefore, we can draw a conclusion: the Cangxi unicorn dance originated in the late Ming Dynasty and gave birth to the original dance pattern in the tiger disaster, showing the unique dance style of Badi, forming rough and brave characteristics, such as its famous burning form. It is famous for its thrilling, all these are the important characteristics of the Ba people's "valiant and martial arts". In the process of the development of unicorn dance, the cultural integration brought about by the filling of Sichuan with Huguang absorbed the skills of southern lions, formed the dual mode of "high platform" + "burning", and became a unique dance form in Cangxi, which is praised by the world. In 2009, Cangxi unicorn dance has become a provincial intangible cultural heritage. 


\section{Summary}

Cangxi is located in Qinba Mountain area. Tiger infestation has been serious since ancient times, and folk beliefs have been formed because of the worship and fear of tigers. Combined with the characteristics of immortals and wild animals such as Kirin, the performance form of southern lions has been integrated, and the local folk imagination and construction have been added to create the unique unicorn dance in Cangxi, which can be traced back to the end of the Ming Dynasty. In the process of more than 400 years of inheritance, the current unicorn dance has been formed through social changes, gradual changes and integration into new dance concepts and dance patterns. The biggest focus of unicorn dance was the form of "fire", which is a typical manifestation of "fire" worship from the perspective of ethnology. The folklore and dance forms contained in the unicorn dance have a certain historical significance, and the historical scenes shown by them and the mentality and ideas of the creators, communicators and adapters are real, which convey the ancient ancestors' fear of nature. However, from the perspective of Cangxi unicorn dance itself, traditional dance has great survival difficulties due to the impact of all kinds of electronic entertainment. At present, the most important thing is the protection and inheritance of unicorn dance, therefore, it is hoped that on the basis of discussing the origin of unicorn dance, this article will enhance the historical details of unicorn dance, explore the pulse of unicorn dance, and know the great value and significance of unicorn dance, so as to arouse people's attention and protection of unicorn dance, and let this provincial intangible cultural heritage continue to be inherited and carried forward by us. At the same time, it is hoped to provide certain reference value for the future research on intangible cultural heritage and unicorn in Sichuan Province.

\section{Fund Project}

This paper is one of the phased research results of the 2017 school level project of Sichuan University of Arts and Science (Ba culture project) "Research on the historical and cultural heritage of Qinba area in Sichuan" (Project No.: 2017BWH002Y).

This paper is one of the phased research results of the project "illustration of intangible cultural heritage in Northeast Sichuan" of Sichuan social science planning project (spread project) in 2019 (project number: SC19KP014).

\section{Conflicts of Interest}

The author declares no conflicts of interest regarding the publication of this paper.

\section{References}

Gao, Y., \& Yao, S. (2007). Chinese Lion Dance. Tianjin: Nankai University Press.

Guo, Q. (1991). Tiger-Shaped Unicorn. Wenbo, 2, 81.

Huang, Y. (2001). The Origin and Flow of Chinese Lion Dance. Sports Culture and His- 
tory, 1, 45-46.

Sun, Y. (1987). Statues of Auspicious Animals in Stone Carvings of Tang Tombs. Western Art, 1, 33-36

Weng, M. (2008). Lion Dance and Kirin Dance in Vietnam: On the Similarities and Differences between Lion Dance and Other Regions in East Asia. National Art, 4, 80-85. 